\title{
Underwater radiated noise characteristic of the hydro-spinna tidal turbine under induced cavitation
}

\author{
Roslynna Rosli ${ }^{\text {a* }}$, Weichao Shi ${ }^{\mathrm{b}}$, Batuhan Aktas ${ }^{\mathrm{b}}$, Rose Norman $^{\mathrm{c}}$, Mehmet Atlar $^{\mathrm{b}}$ \\ ${ }^{a}$ Universiti Teknologi Brunei, Bandar Seri Begawan BE1410, Brunei Darussalam \\ ${ }^{b}$ University of Strathclyde, Glasgow G4 OLZ, United Kingdom \\ ${ }^{c}$ Newcastle University, Newcastle upon Tyne NE1 7RU, United Kingdom
}

\begin{abstract}
Over the past decade, the development of marine current turbines has progressed rapidly with prototypes and fullscale devices being deployed in the actual environment. With research focusing on the hydrodynamic and design aspects of the technologies used, little is known of the impact of marine current turbine operation on marine life and the environment. This paper looks at the Underwater Radiated Noise (URN) produced from the operation of the Hydro-Spinna turbine which is a horizontal-axis type concept design under development at Newcastle University. URN measurements were taken from a $280 \mathrm{~mm}$ diameter Hydro-Spinna model. The URN measurement was part of a comprehensive investigation conducted on the turbine model, where the local pressure in the tunnel was reduced to induce cavitation to study its characteristics. The noise data was found to correspond to the cavitation observation where the noise increases as more cavitation developed. In addition, only tip vortex cavitation was observed during the investigation indicating that this is the only cavitation characteristic of the Hydro-Spinna turbine. As more tip vortex cavitation was observed, the URN results exhibit an apparent trend, whereby the sound pressure level (SPL) increased and the frequency shifted towards the lower frequency region.
\end{abstract}

Keywords: Tidal turbine, tidal turbine operation, underwater radiated noise, turbine radiated noise, noise measurement, cavitation, turbine cavitation

\section{Introduction}

\subsection{Tidal turbine and underwater radiated noise}

Tidal energy has experienced massive development recently to exploit the energy available in tides, introducing a plethora of energy converting technologies. Extensive research projects concentrating on the design, technical and hydrodynamic performance of tidal energy devices are aplenty. The European Marine Energy Centre (EMEC) in Scotland is the heart of tidal energy development with various prototypes already deployed and assessed in real sea conditions.

While most research focuses on the technical aspects of the field, little is known of the impact tidal current turbines have on the marine environment. Parallel experiences on the environmental impacts, specifically Underwater Radiated Noise (URN), of other marine applications such as marine propellers can be considered. Shipping activities and operation of marine propellers are known to produce URN and disturb the ambient acoustic of the environment they operate in [1-3]. Hence, in other sectors in the marine industries, research projects on the URN are soundly performed such as the SILENV (Ships oriented Innovative soLutions to rEduce Noise and Vibrations) [4] to assess and mitigate the URN impacts on the marine environment.

A few research projects have also embarked on the measurement and investigation of tidal turbine URN and its impacts [5, 6]. The URN generated by tidal turbine operations, installation and

\footnotetext{
* Manuscript received May 14, 2018; revised May 4, 2019.

Corresponding author. Tel.: +6732461020 ; E-mail address: roslynna.rosli@utb.edu.bn

doi: $10.12720 /$ sgce.8.4.415-421
} 
decommissioning will undoubtedly affect the ambient acoustic it is deployed in. As most marine animals communicate using sounds of different pitch and frequency, the disturbance to the ambient acoustic may affect their livelihood [6-8]. It is important to understand the level of URN that tidal turbines produce.

This paper considers the URN profile of a model novel tidal current turbine, the Hydro-Spinna [9, 10] under different cavitation conditions. The work was a part of an extensive investigation to study the cavitation characteristics of the Hydro-Spinna turbine. Together with this investigation, the URN produced by the turbine was also used to explore the relationship of the turbine cavitation and generated noise. The URN profiles presented are those for the conditions where tip vortex cavitation was observed.

\subsection{Hydro-Spinna turbine, HS280 model}

The Hydro-Spinna turbine presents a unique helical design in which the blades are extended in the axial direction. The blades are each of a cardioidal shape [11]. A new parameter, the Pitch Length (P), describes the length at which the turbine is extended in the axial direction. For this investigation, the HS280 model has a diameter of $0.28 \mathrm{~m}$ and a pitch length of $0.12 \mathrm{~m}$ giving a Pitch length to Diameter ratio (P/D) of 0.43 . The blades have the cross sectional profile of a NACA 0006.
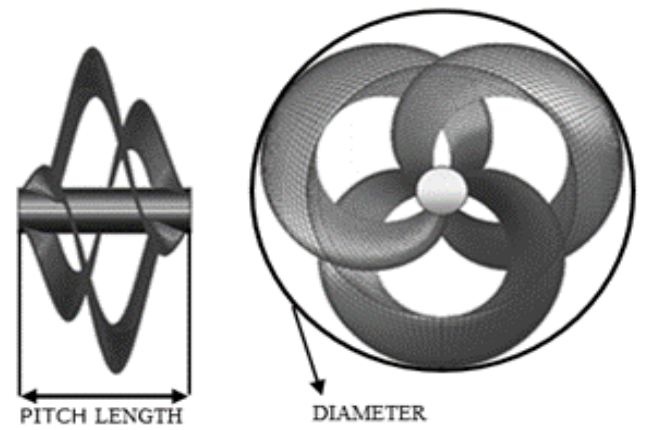

Fig. 1. The Hydro-Spinna HS280 turbine model

\section{Test Procedure}

\subsection{Test facilities}

The investigations were performed in the Emerson Cavitation Tunnel at Newcastle University. Two high-speed cameras were employed to capture the cavitation behaviour of the turbine. Both cameras were connected to a Plasma Lite 400 light to illuminate the tunnel. The noise level was measured using a Bruel and Kjaer (B\&K) Type 8103 miniature hydrophone located $0.38 \mathrm{~m}$ downstream of the turbine. The noise data was processed in the built-in B\&K PULSE Type 3023 system into 1/3 Octave Band format.

\subsection{Experimental procedure}

The tunnel pressure was reduced from $850 \mathrm{~mm} \mathrm{Hg}$ down to vacuum pressure of $250 \mathrm{~mm} \mathrm{Hg}$ at an interval of $100 \mathrm{~mm} \mathrm{Hg}$. At each pressure condition, results for a complete set of turbine Tip Speed Ratios (TSR) were taken with the test matrix described in Table 1. Both cavitation observation and URN measurement were conducted simultaneously. Cavitation number were calculated at $0.7 \mathrm{x}$ Radius of the turbine defined in equation (1) below.

$$
\sigma_{0.7 R}=\frac{P_{T}-\rho g(0.7 R)-P_{V}}{0.5 \rho W_{0.7}{ }^{2}}
$$

where $\boldsymbol{W}$ is the resultant flow velocity at $0.7 \mathrm{R}$ defined as $W_{0.7}=\sqrt{(\Omega \times 0.7 R)^{2}+U_{0}^{2}}$, the term $P_{T}-\rho g(0.7 R)$ is the static pressure above the location $0.7 R, P_{T}$ is the tunnel pressure, $\rho$ is the water density, $U_{0}$ is the flow velocity, and $\Omega$ is the rotational velocity of the turbine. 


\subsection{Presentation of $U R N$ data}

The noise Sound Pressure Level (SPL) measured from the investigation were first corrected to $1 \mathrm{~Hz}$ bandwidth and $1 \mathrm{~m}$ source level to maintain the practice of standard propeller noise measurement [2] as given in equation (2) and (3) below. The corrected data are further refined by removing the background noise as defined in equation (4), taking into account the expected uncertainty of measurements of $3 \mathrm{~dB}$ and less [12].

Table 1. Test matrix for the investigation with highlighted conditions where cavitation was observed

\begin{tabular}{|c|c|c|c|c|}
\hline Run & Tunnel Pressure & Tunnel Velocity & TSR Range & Cavitation No. @0.7R \\
\hline \multirow[t]{6}{*}{1} & \multirow{6}{*}{$\begin{array}{l}850 \mathrm{~mm} \mathrm{Hg} \\
\text { (Normal tunnel pressure) }\end{array}$} & \multirow{42}{*}{$3 \mathrm{~m} / \mathrm{s}$} & 0 & 24.3 \\
\hline & & & 1 & 16.2 \\
\hline & & & 2 & 8.02 \\
\hline & & & 3 & 4.51 \\
\hline & & & 4 & 2.67 \\
\hline & & & 5 & 1.80 \\
\hline \multirow[t]{6}{*}{2} & \multirow{6}{*}{$750 \mathrm{~mm} \mathrm{Hg}$} & & $\overline{0}$ & 21.5 \\
\hline & & & 1 & 14.2 \\
\hline & & & 2 & 6.96 \\
\hline & & & 3 & 3.94 \\
\hline & & & 4 & 2.39 \\
\hline & & & 5 & 1.63 \\
\hline \multirow[t]{6}{*}{3} & \multirow[t]{6}{*}{$650 \mathrm{~mm} \mathrm{Hg}$} & & 0 & 18.5 \\
\hline & & & 1 & 12.5 \\
\hline & & & 2 & 6.22 \\
\hline & & & 3 & 3.36 \\
\hline & & & 4 & 2.03 \\
\hline & & & 5 & 1.39 \\
\hline \multirow[t]{6}{*}{4} & \multirow[t]{6}{*}{$550 \mathrm{~mm} \mathrm{Hg}$} & & 0 & 15.6 \\
\hline & & & 1 & 10.2 \\
\hline & & & 2 & 5.15 \\
\hline & & & 3 & 2.84 \\
\hline & & & 4 & 1.77 \\
\hline & & & 5 & 1.16 \\
\hline \multirow[t]{6}{*}{5} & \multirow[t]{6}{*}{$450 \mathrm{~mm} \mathrm{Hg}$} & & 0 & 12.6 \\
\hline & & & 1 & 8.37 \\
\hline & & & 2 & 4.18 \\
\hline & & & 3 & 2.26 \\
\hline & & & 4 & 1.41 \\
\hline & & & 5 & 0.95 \\
\hline \multirow[t]{6}{*}{6} & \multirow[t]{6}{*}{$350 \mathrm{~mm} \mathrm{Hg}$} & & 0 & 9.19 \\
\hline & & & 1 & 6.48 \\
\hline & & & 2 & 3.23 \\
\hline & & & 3 & 1.75 \\
\hline & & & 4 & 1.10 \\
\hline & & & 5 & 0.73 \\
\hline \multirow[t]{6}{*}{7} & \multirow[t]{6}{*}{$250 \mathrm{~mm} \mathrm{Hg}$} & & 0 & 6.72 \\
\hline & & & 1 & 4.66 \\
\hline & & & 2 & 2.37 \\
\hline & & & 3 & 1.25 \\
\hline & & & 4 & 0.75 \\
\hline & & & 5 & 0.50 \\
\hline \multicolumn{5}{|c|}{$\mathrm{SPL}_{1}=\mathrm{SPL}_{m}-10 \log \Delta f$} \\
\hline & & SPL $=$ & $L_{1}+20 \log (r)$ & \\
\hline
\end{tabular}

where SPL is the Sound Pressure Level in $1 \mathrm{~Hz}$ band in $\mathrm{dB}$ relative to $1 \mu \mathrm{Pa}$ at $1 \mathrm{~m}, \mathrm{r}$ is the distance of the location of the hydrophone from the turbine centreline, SPL1 is the Sound Pressure Level in $1 \mathrm{~Hz}$ band in 
$\mathrm{dB}$ relative to $1 \mu \mathrm{Pa}$, SPLm is the Sound Pressure Level in $1 / 3$ Octave band in $\mathrm{dB}$ relative to $1 \mu \mathrm{Pa}$, and $\Delta f$ is the frequency bandwidth for the $1 / 3$ Octave band for each centre frequency.

$$
\mathrm{SPL}_{\mathrm{N}}=10 \log \left[10^{\left(\mathrm{SPL}_{T} / 10\right)}-10^{\left(\mathrm{SPL}_{R} / 10\right)}\right]
$$

where $\mathrm{SPL}_{\mathrm{N}}$ is the net Sound Pressure Level, $\mathrm{SPL}_{\mathrm{T}}$ is the total Sound Pressure Level and $\mathrm{SPL}_{\mathrm{B}}$ is the background noise Sound Pressure Level.

\section{Results and Discussion}

In order to make sense of the data and analysis, it is important to highlight that the Hydro-Spinna model investigated produced a maximum power coefficient of 0.38 at $T S R=3$, while the maximum thrust coefficient was 1.2 at $T S R=1$. The thrust coefficient trend of the Hydro-Spinna turbine, as shown in Fig. 2 , is unique such that it reaches the peak at $T S R=1$ and then decreases as the $T S R$ increases. It is believed that for $T S R \leqslant 1$, the high solidity of the Hydro-Spinna produced the high thrust coefficients. The decrease of the thrust coefficient at $T S R>1$ is thought to be caused by the nature of the turbine blade design itself and the interaction of the resultant force between the upstream and downstream sections of the turbine [13]. In contrast, thrust coefficient normally increases with increasing TSRs in other conventional tidal turbine $[14,15]$.

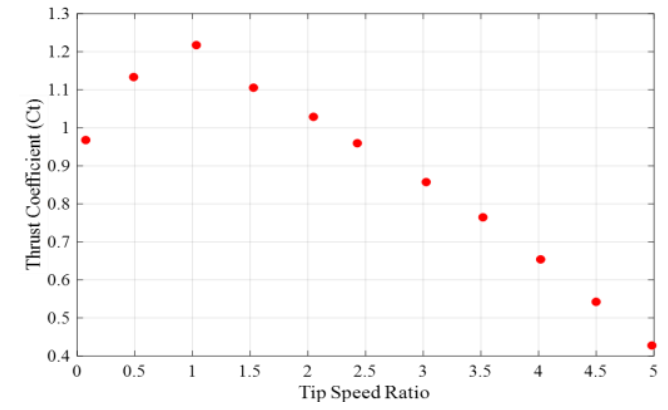

Fig. 2. Thrust coefficient profile of the Hydro-Spinna

\subsection{Cavitation Observation}

At normal tunnel pressure, very weak intermittent vortex cavitation was observed at $T S R=1$ while no cavitation was observed at other values. As the tunnel pressure was reduced to $750 \mathrm{~mm} \mathrm{Hg}$, the vortex cavitation at $T S R=1$ developed further and was more observable. The cavitation further developed as the tunnel pressure was further reduced. Fig. 3 shows the description of the type of cavitation observed in the Cavitation Number against TSR plot. As cavitation was observed mostly at the TSR range between 1 and 2 for the vacuum pressure between 750 to $450 \mathrm{~mm} \mathrm{Hg}$ it is concluded that cavitation occurs when the thrust coefficient was at its highest. In conventional turbines, cavitation is usually observed with decreasing cavitation number [14] which is inapplicable in the case of the Hydro-Spinna as its cavitation behaviour is dependent on the thrust coefficient instead of the cavitation number.

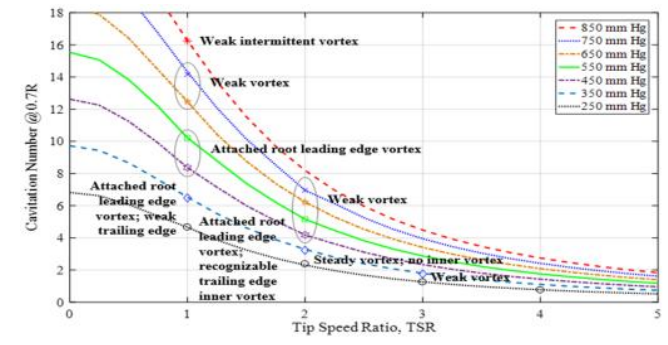

Fig. 3. Breakdown of the cavitation observed and its corresponding TSR and Cavitation Number

Additionally, Fig. 4 presents the development of the vortex cavitation at $T S R=1$, that originated from 
the leading edge of the blade at the root section, as the tunnel pressure was further decrease to high vacuum pressures. For each pressure condition, most developed tip vortex cavitation was observed at TSR $=1$ which coincides with the maximum thrust coefficient. Tip vortex cavitation was also observed at TSR $=2$ at vacuum pressure of 350 and $250 \mathrm{~mm} \mathrm{Hg}$. Since cavitation was consistently observed at $T S R=1$, these conditions were used to assess the relationship of the tip vortex cavitation with the URN generated.

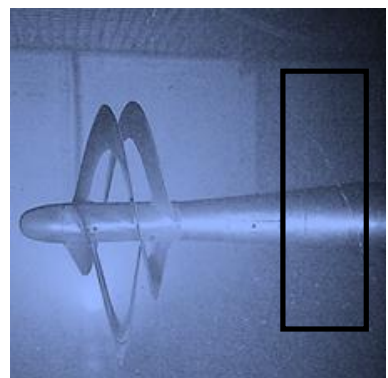

$850 \mathrm{~mm} \mathrm{Hg}, T S R=1$

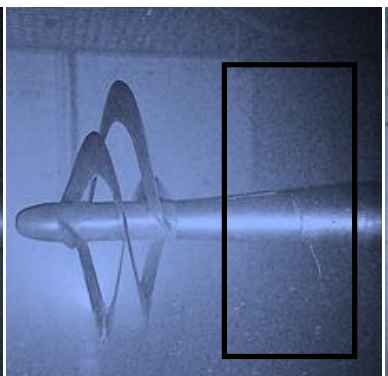

$750 \mathrm{~mm} \mathrm{Hg}, T S R=1$

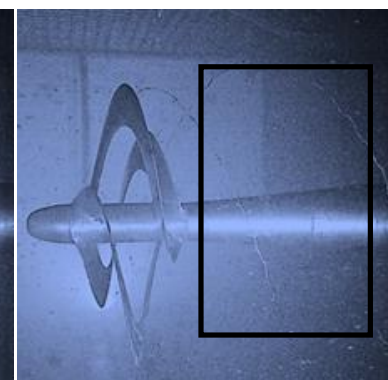

$650 \mathrm{~mm} \mathrm{Hg}, T S R=1$

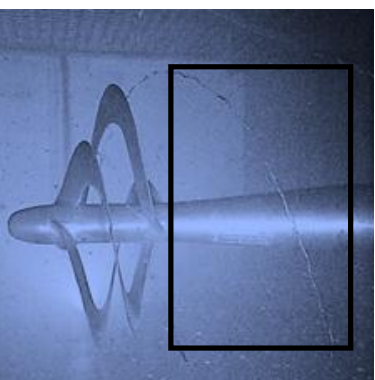

$550 \mathrm{~mm} \mathrm{Hg}, T S R=1$

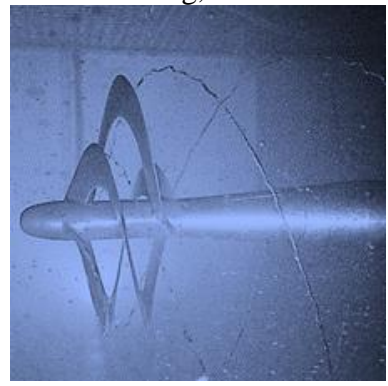

$450 \mathrm{~mm} \mathrm{Hg}, T S R=1$

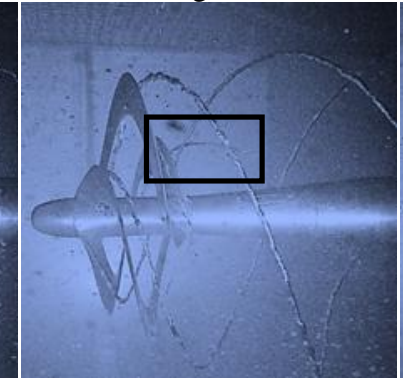

$350 \mathrm{~mm} \mathrm{Hg}, T S R=1$

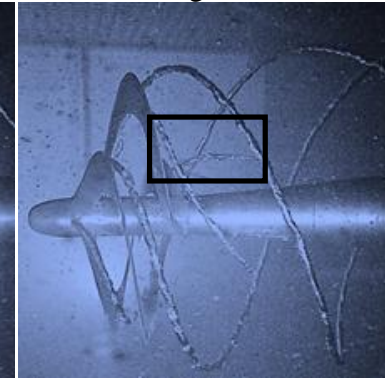

$250 \mathrm{~mm} \mathrm{Hg}, T S R=1$

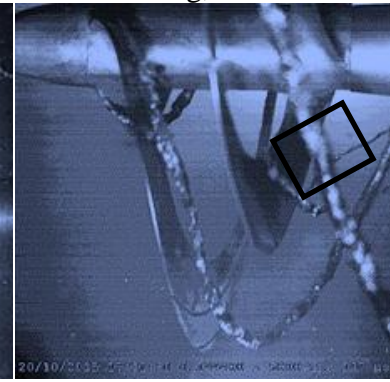

$250 \mathrm{~mm} \mathrm{Hg}, T S R=1$

Fig. 4. Development of the vortex cavitation with decreasing pressure. The black rectangle for 350 and $250 \mathrm{~mm} \mathrm{Hg}$ indicated the development of the second tip vortex cavitation

At tunnel pressure of $350 \mathrm{~mm} \mathrm{Hg}$, a second tip vortex cavitation was observed originating from the inner trailing edge at the highest turbine radius. At a higher vacuum pressure of $250 \mathrm{~mm} \mathrm{Hg}$, the second tip vortex cavitation was more noticeable. Besides tip vortex cavitation, no other types of cavitation occured. This is an important characteristic of the Hydro-Spinna operation as tip vortex cavitation has minimal impact on turbine structural integrity as well as generating less noise than the other types of cavitation $[14,16,17]$.

\subsection{URN measurement}

As mentioned previously, the URN data presented in this paper is that of the TSR $=1$ conditions for all tunnel pressures. This is because, at this TSR, cavitation was consistently observed and there was a clear trend of the development of the tip vortex cavitation. Fig. 5 shows the URN generated by the turbine characterised by the vortex cavitation.

The presence and intensity of the tip vortex cavitation was in parallel with the URN measurement. The Sound Pressure Level (SPL) recorded not only increased with increasing vacuum, but it also shifted towards the lower frequency region as more vortex cavitation developed. For example, at $450 \mathrm{~mm} \mathrm{Hg}$, the SPL recorded was between 200 and $1200 \mathrm{~Hz}$ with maximum SPL just below $115 \mathrm{~dB}$. Whereas at $250 \mathrm{~mm}$ $\mathrm{Hg}$, the frequency shifted to the lower region between 50 and $1000 \mathrm{~Hz}$ with a higher maximum SPL of $119 \mathrm{~dB}$. This unique sound profile of the tip vortex cavitation supported the finding by Pennings, et al. $[18,19]$ where the same sound signature was obtained. 


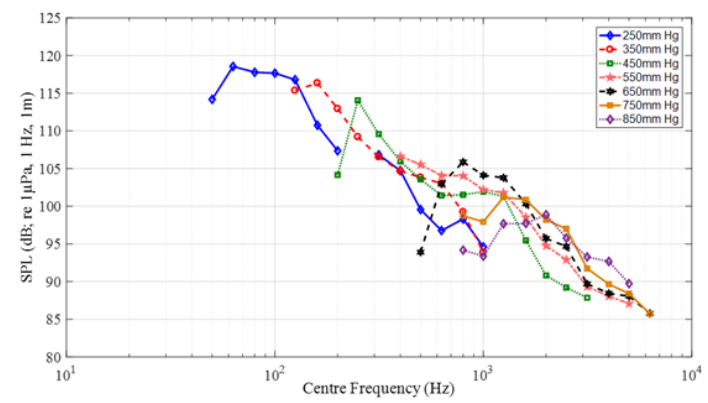

Fig. 5. Net $1 / 3$ Octave Band Level for TSR $=1$ at all pressure conditions

\section{Conclusions}

This paper presented the cavitation characteristic of the Hydro-Spinna turbine and the corresponding URN profile generated. At each tunnel pressure, most cavitation was observed at $T S R=1$ corresponding to the maximum thrust condition. Occurrence and intensity of the tip vortex cavitation correlated well with the URN measurement. The SPL recorded increases with increasing occurrence of cavitation. Simultaneously, the URN also shifted towards the lower frequency region when more cavitation was observed, hence, confirming the unique sound profile credited to tip vortex cavitation as previously claimed by other research.

\section{References}

[1] Frisk GV. Noiseonomics: The relationship between ambient noise levels in the sea and global economic trends. Scientific Reports, 2012.

[2] Aktas B, Atlar M, Turkmen S, Shi W, Sampson R, Korkut E, Fitzsimmons P. Propeller cavitation noise investigations of a research vessel using medium size cavitation tunnel tests and full-scale trials. Ocean Engineering, 2016; 120: 122-135.

[3] Aktas B, Atlar M, Turkmen S, Korkut E, Fitzsimmons P. Systematic cavitation tunnel tests of a propeller in uniform and inclined flow conditions as part of a round robin test campaign. Ocean Engineering, 2016; 120: 136-151.

[4] SONIC, "Suppression of underwater Noise Induced by Cavitation. In European Union Framework programme 7. FP7-SST2012-RTD-1- SST.2012.1.1-1. - Assessment and mitigation of noise impacts of the maritime transport on the marine environment (coordinated topic within the framework of the "Ocean of Tomorrow"), 2012.

[5] Shi W, Atlar M, Rosli R, Aktas B, Norman R. Cavitation observations and noise measurements of horizontal axis tidal turbines with biomimetic blade leading-edge designs. Ocean Engineering, 2016; 121: 143-155.

[6] Pine MK, Jeffs AG, Radford CA. Effects of underwater turbine noise on crab larval metamorphosis. Advances in Experimental Medicine and Biology, 2016; 847-852.

[7] White P, Pace F. The impact of underwater ship noise on marine mammals. Presented at: 2010 1st IMarEST Ship Noise and Vibration Conference.

[8] Spiga I, Cheesman S, Hawkins A, Perez-Dominguez R, Roberts L, Hughes D, Elliott M, Nedwell J, Bentley M. Understanding the Scale and Impacts of Anthropogenic Noise upon Fish and Invertebrates in the Marine Environment. SoundWaves Consortium Technical Review (ME5205), 2012.

[9] Rosli R, Shi W, Norman R, and Atlar M. Cavitation tunnel investigation on the performance, cavitation and noise generation of marine current turbine: Hydro-Spinna. Presented at: 2015 The 4th International Conference on Advance Model Measurement Technologies for the Maritime Industry, Istanbul, Turkey.

[10] Rosli R. Experimental and numerical hydrodynamic analysis of a novel tidal turbine, the Hydro-Spinna. School of Agriculture and Engineering, Newcastle University, United Kingdom, 2018.

[11] Rosli R, Norman R, and Atlar M. Computational Investigation using a simple RANS model on the performance of a novel marine turbine: Hydro-Spinna. Presented at: 2014 GRAND Renewable Energy, Tokyo, Japan.

[12] Bertschneider H, Bosschers J, Choi GH, Ciappi E, Farabee T, Kawakita C, and Tang D. 27th ITTC Report of Specialist Committee on Hydrodynamic Noise. International Towing Tank Conference, Copenhagen, Denmark, 2012.

[13] Rosli R, Norman R, Atlar M. Experimental investigations of the Hydro-Spinna turbine performance. Renewable Energy, 2016; 99: 1227-1234.

[14] Bahaj AS, Molland AF, Chaplin JR, Batten WMJ. Power and thrust measurements of marine current turbines under various hydrodynamic flow conditions in a cavitation tunnel and a towing tank. Renewable Energy, 2007; 32(3): 407-426.

[15] Clarke JA, Connor G, Grant AD, Johnstone CM. Design and testing of a contra-rotating tidal current turbine," Proceedings of the Institution of Mechanical Engineers. Part A: Journal of Power and Energy, 2007; 221: 171-179.

[16] Sharma SD, Mani K, Arakeri VH. Cavitation noise studies on marine propellers. Journal of Sound and Vibration, 1990; 
138(2): 255-283.

[17] Wang D, Atlar M, Sampson R. An experimental investigation on cavitation, noise, and slipstream characteristics of ocean stream turbines," Proceedings of the Institution of Mechanical Engineers. Part A: Journal of Power and Energy, 2007; 221(2): 219-231.

[18] Pennings P, Westerweel J, Terwisga TV. Sound signature of propeller tip vortex cavitation. Journal of Physics: Conference Series, 2015; 656: 012186.

[19] Pennings P, Westerweel J, Terwisga TV. Cavitation tunnel analysis of radiated sound from the resonance of a propeller tip vortex cavity. International Journal of Multiphase Flow, 2016; 83 : 1-11. 